\title{
Effect of Diabetes on Severity of Illness, Length of Hospital Stay and Mortality among Patients Brought by Emergency Medical System (EMS)
}

\author{
Prasad Ananta Rajhans ${ }^{1}$, Priya Yogesh Kulkarni*2 ${ }^{* 2}$ Dhananjay Shrakrishna Kelkar ${ }^{3}$, Sameer Arvind Jog ${ }^{4}$, \\ Gouri Ranade ${ }^{5}$, Sonal Utpat ${ }^{6}$, Varsha Hande ${ }^{7}$
}

Prasad Ananta Rajhans ${ }^{1}$, Priya Yogesh Kulkarni*2, Dhananjay Shrakrishna Kelkar ${ }^{3}$, Sameer Arvind $\mathrm{Jog}^{4}$, Gouri Ranade ${ }^{5}$, Sonal Utpat ${ }^{6}$, Varsha Hande $^{7}$

'FICCM,Chief Intensivist, Deenanath Mangeshkar Hospital and research centre, Pune, INDIA. ${ }^{2}$ Community Medicine, SMBT Medical College, Nasik, Maharashtra, INDIA.

${ }^{3}$ Medical director, Deenanath Mangeshkar Hospital and research centre, Pune, INDIA.

${ }^{4}$ Consultant Intensivist, Deenanath Mangeshkar Hospital and research centre, Pune, INDIA. ${ }^{5}$ Consultant Intensivist, Deenanath Mangeshkar Hospital and research centre, Pune, INDIA. ${ }^{6}$ Head of Emergency Department, Deenanath Mangeshkar Hospital and research centre, Pune, INDIA.

'Senior Emergency medical officer, Deenanath Mangeshkar Hospital and research centre, Pune, INDIA.

Correspondence Dr. Priya Yogesh Kulkarni

Associate Professor, Community Medicine, PIMS \& RC, Islampur, Maharashtra, INDIA.

Email: dr_pdkulkarni@yahoo.co.in

History

- Submission Date: 03-11-2016;

- Revised Date: 26-06-2017

- Accepted Date: 27-07-2017;

DOI : 10.5530/ijmedph.2017.3.32

Article Available online

http://www.ijmedph.org/v7/i3

\section{Copyright}

(C) 2017 Phcog.Net. This is an openaccess article distributed under the terms of the Creative Commons Attribution 4.0 International license.

\begin{abstract}
Background: In view of growing epidemic of diabetes it is important to assess how it affects various parameters of the disease especially in developing countries. Aim: To compare severity of illness, length of various hos pital stays and mortality in diabetics and non-diabetics. Material and methods: It was hospital record based study carried out at Deena Nath Mangeshkar Hospital and research centre, Pune. Patients admitted to intensive care unit from 1st January 2013 to 31st December 2014 through emergency medical services were enrolled. Socio-demographic information, chief complaints, diabetes status, co-morbidities, Glasgow coma scale at initial examination, definitive diagnosis, and length of stay in intensive care unit, wards and total hospital stay and outcome of the patient were recorded from available data. Results: Data 1951 patients were analyzed. 37.6\% were females, $62.4 \%$ were males. $45.8 \%$ were diabetics, out of them $28.81 \%$ were new cases. Though, co-morbidities were significantly more among diabetics, they were significantly less to have severe condition according to Glasgow coma scale $(p=0.003)$. Diabetics had significantly less intensive care unit stay than non-diabetics (Mean 5.98 days $( \pm 6.579)$ vs $7.52( \pm 9.293)$ respectively, $p=0.008)$. Ward stay and total hospital stay did not differ. Mortality did not differ among diabetics and non-diabetics $(23.8 \%$ and $23.6 \%$ respectively, $p=0.947$ ). Conclusion: Though proportion of diabetics was very high among study subjects, diabetes did not contribute to any adverse outcome or length of hospital stay.

Key words: Diabetes (DM), Severity of DM, Length of hospital stay (LOS), EMS.
\end{abstract}

\section{INTRODUCTION}

Epidemic of Diabetes is rapidly increasing all over the world. Most dramatic increase is being seen in low- and middle-income countries. ${ }^{1}$ This reflects an increase in associated risk factors such as being overweight or obese, recent changes in lifestyles, environmental factors along with genetic factors are at play. ${ }^{2}$ Over the past decade, diabetes prevalence has risen faster in low- and middle-income countries than in high-income countries. The percentage of deaths attributable to high blood glucose or diabetes that occurs prior to age 70 is higher in low- and middleincome countries than in high-income countries. ${ }^{3}$ Globally, its prevalence has nearly doubled since 1980 , rising from $4.7 \%$ to $8.5 \%$ in the adult population. Number of adults with diabetes was estimated to be 422 million in 2014 as compared to 108 million in 1980. ${ }^{3}$ The World Health Organization also predicted a $50 \%$ increase in deaths from diabetes over next 10 years, and by 2030 , diabetes is projected to be the seventh leading cause of death. ${ }^{4}$
India is the diabetes capital of the world where every adult over the age of 40 is at risk. India had 69.2 million people living with diabetes (8.7\%) as per the 2015 data. Of these, it remained undiagnosed in more than 36 million people. Number is estimated to increase to 70 million by 2025 . This suggests that every fifth diabetic in the world would be an Indian. ${ }^{5}$

In view of alarming situation of diabetes, theme of World Health Day 2016 was 'Scale up prevention, strengthen care, and enhance surveillance of diabetes' so that individuals in every community get involved in activities that can lead to better awareness of diabetes. ${ }^{6}$

As it is a chronic disease, Diabetes Mellitus (DM) and its complications bring about substantial economic loss to people with diabetes and their families, health systems and national economies through direct medical costs and loss of work and wages. When diabetes is uncontrolled, it has dire consequences for health and well-being.
Cite this article : Rajhans PA, Kulkarni PY, Kelkar DS, Jog SA, Ranade G, Utpat S, Hande V. Effect of Diabetes on Severity of Illness, Length of Hospital Stay and Mortality among Patients Brought by Ems. Int J Med Public Health. 2017;7(3):156-61. 
Due to micro and macrovascular changes, diabetics have significantly greater risk of acute and chronic complications, including hypertension, cardiovascular, kidney, eye, and nerve diseases. They contribute significantly to hospitalization and medical expenditures. ${ }^{7,8}$

Diabetics can present themselves to emergency departments with variety of symptoms and co-morbidities. Its increased prevalence, earlier age of incidence, growing population with changing age structure in countries like India, we expect increase in diabetic patients among emergency departments.

Diabetes may alter the course of illness, length of hospital stays (LOS) and mortality. There is a conflict in literature about mortality in diabetics, with studies showing increased risk, ${ }^{9,10}$ decreased risk $^{11}$ or neutral risk. ${ }^{12,13}$

Many studies reported alterations during illness because of diabetes. These studies also reported three-fold higher (18.9/1000 person years) mortality in diabetes compared to non-diabetic (5.3/1000 person-years, $\mathrm{p}=0.004) .{ }^{14}$

Present study was designed to assess how diabetes affect severity of illness, length of hospital stays and mortality among patients who called emergency ambulance services of Deena Nath Mangeshkar Hospital and Research Centre (DMHRC), Pune, Maharashtra, India.

\section{MATERIAL AND METHODS}

This is an observational record based study to assess the effect of diabetes on severity, mortality and length of stay among patients in a tertiary care corporate hospital. Study was carried out on the patients who called and utilized EMS of DMHRC during $1^{\text {st }}$ January 2013 to $31^{\text {st }}$ December 2014. DMHRC is situated at the heart of the city surrounded by affluent residential areas as well as urban slums.

We recruited all the patients who called EMS of DMHRC during the study period. Information regarding socio-demographic variables, whether known case of diabetes, whether patient was diabetic as per investigations done during present episode of illness, co-morbidities, severity of illness, length of ICU, ward and total hospital stay etc was collected from scanned copies of emergency, ICU and ward sheets by a trained person with medical background. Patients who died at the scene before arrival of EMS team and patients having incomplete records were excluded from the study.

Patients with previously diagnosed DM were considered those who were on diet, oral hypoglycemic agents or taking insulin therapy. Newly diagnosed DM patients were considered those with the value of glycemic on admission above $200 \mathrm{mg} / \mathrm{dl}$ in first $24 \mathrm{~h}^{15}$

Length of ICU stay was number of days admitted in ICU before shifting the patients to wards or at home or death. Similarly ward stay was number of days before discharging patient at home or against medical advice or death. Total hospital stay was summation of length of ICU stay and ward stay in days.

Data were entered in Microsoft excel spreadsheet and imported to SPSS 15.0 data editor for further analysis. Qualitative variables were reported as percentages and quantitative as mean and SD. Student's t test is used to compare length of stay LOS in ICU, hospital and in-total among diabetics and non-diabetics while chi square test was used to assess mortality difference. Level of significance was fixed at 0.05 level.

\section{RESULT}

We analyzed total 1951 patients utilizing hospital's EMS services during the study period.

Baseline characteristics of the patients
$37.6 \%(733 / 1951)$ were females, $62.4 \%$ (1218/1951) were males. Mean age noted was 61.09 years $(+22.054)$. We included all the age groups and majority (65.7\%) was between $40-80$ years of age, $16.5 \%$ were between 81- 101 years of age and $17.8 \%$ patients were between 0 - 40 years Figure 1.

Majority, (1928/1951) were Hindus. 95.5\% (1864/1951) from Pune, and remaining $4.5 \%(87 / 1951)$ were non-residents of Pune. $94.5 \%$ $(1843 / 1951)$ were from urban areas, while $1.2 \%$ (23/1951) and $4.4 \%$ $(85 / 1951)$ were from urban slums and rural areas around Pune respectively. $96.5 \%$ (/1951) calls were from within 15 kilometers of radius from the DMHRC.

\section{Diabetes and Uncontrolled diabetes among study subjects}

$45.8 \%(894 / 1951)$ were diabetics out of which $78.19 \%(699 / 894)$ were known cases of diabetes while $28.81 \%$ (195/ 894) cases diabetes was detected during transport by EMS or later on while investigations in ICU/ wards. Figure 1 Diabetics were significantly more in the age group of $>60$ years ( $58.8 \%$ diabetics vs $24.9 \%$ non-diabetics). Rural/urban difference was noted, diabetics were more likely to reside in urban area $(46.79 \%$ vs $24.71 \%)$. There was no gender difference noted. Figure 2. 5.1\% $(100 / 1951)$ patients had uncontrolled diabetes. 96 were known cases while 4 were diagnosed while investigations in EMS/ICU/ wards. Majority, $82 / 100$, had altered sensorium as a purpose to call EMS. $(\mathrm{p}<0.001)$. 7/100 had BSL $>300 \mathrm{mg} / \mathrm{dl}, 66 / 100$ had BSL $<70 \mathrm{mg} / \mathrm{dl}, 6 / 100$ had metabolic disturbances with DKA.

\section{Mode of presentation and co-morbidities and definitive diagnosis}

Significantly more diabetics had breathlessness ( $54.4 \%$ vs $43 \%)$, altered sensorium ( $53.6 \%$ vs $40.4 \%$ ) and dyspnea $(56.2 \%$ vs $45.3 \%)(\mathrm{p}<0.001$, $<0.001$ and 0.045 respectively). Table 1 Significantly less diabetics had sudden headache (13.3 vs 46.1 ) and high-grade fever (38.9 vs 46.5 ) with $\mathrm{p}$ values 0.012 and 0.048 respectively Table 1 .

Other co-morbidities in the form of Hypertension, other cardiovascular abnormalities, COPD, CKD and history of CVA were significantly more among diabetics $(\mathrm{p}<0.001$, except for COPD, $\mathrm{p}=0.027)$ Table 2.

\section{Severity of diabetics and non-diabetics according to GCS}

25.1\% (490/1794) EMS patients had severe GCS. During the initial examination, significantly less number of diabetics $(24.0 \%, 203 / 845)$ showed severe GCS than non-diabetics $(30.2 \%, 287 / 949)$ with $\mathrm{p}=0.003$, $\mathrm{OR}=0.841$ and $95 \% \mathrm{CI}=0.747-0.948$ Figure 3.

GCS did not differ between patients with uncontrolled DM and DM in controlled status. $17.7 \%$, (17/96) patients with uncontrolled diabetics had severe GCS while $24.8 \%$, (186/749) in diabetics with controlled status had severe GCS. ( $\mathrm{p}=0.124)$. Significantly less number of new cases of diabetes had severe GCS $(17.3 \%, 33 / 189)$ as compared to previously known diabetics $(25.9 \%, 170 / 656)$ with $\mathrm{p}=0.017, \mathrm{OR}=1.484,95 \% \mathrm{CI}=$ 1.061 - 2.077) Figure 4.

\section{LOS in ICU, wards and total}

Mean total ICU stay among diabetics $(n=366)$ was 5.98 days $(+6.579$, $\min =1, \max =56)$ which was significantly less than among non-diabetics $(\mathrm{n}=389), 7.52(+9.293, \min =1, \max =64)(\mathrm{p}=0.008)$ Figure 5.

Mean ward stay did not differ among diabetics and non-diabetics $(\mathrm{p}=0.407)$. For diabetics $(\mathrm{n}=299)$ it was $5.93(+5.281)$ days $(\mathrm{min}=1$, $\max =39)$ and for non-diabetics $(\mathrm{n}=263)$ it was $5.58(+4.580)$ days $(\min =1, \max =31)$ Figure 6. 


\begin{tabular}{|c|c|c|c|c|c|c|}
\hline Chief complaints & & DM & No DM & Total & $P$ value & OR $(95 \% \mathrm{Cl})$ \\
\hline \multirow{2}{*}{$\begin{array}{l}\text { CVS related (Sweating, chest pain } \\
\text { and / or palpitations) }\end{array}$} & Yes & $111(49.8)$ & $112(50.2)$ & $223(100)$ & 0.208 & \\
\hline & No & $783(45.3)$ & $945(54.7)$ & $1728(100)$ & & \\
\hline Breathlessness & Yes & $262(54.4)$ & $220(45.6)$ & $482(100)$ & $<0.001^{\star}$ & $1.263(1.142-1.397)$ \\
\hline GIT Related & No & $785(45.8)$ & $926(54.2)$ & $1711(100)$ & & \\
\hline \multirow[t]{2}{*}{ Altered sensorium } & Yes & $429(53.6)$ & $372(46.4)$ & $801(100)$ & $<0.001^{\star}$ & $1.325(1.204-1.457)$ \\
\hline & No & $465(40.4)$ & $685(59.6)$ & $1150(100)$ & & \\
\hline Sudden Headache & Yes & $2(13.3)$ & $13(86.7)$ & $15(100)$ & $0.012^{* *}$ & $0.289(0.080-1.052)$ \\
\hline High grade fever & No & $822(46.5)$ & $944(53.5)$ & $1766(100)$ & & \\
\hline \multirow[t]{2}{*}{ Seizures } & Yes & $55(40.1)$ & $82(59.9)$ & $137(100)$ & 0.167 & \\
\hline & No & $839(46.3)$ & $975(53.7)$ & $1814(100)$ & & \\
\hline \multirow[t]{2}{*}{ GUT related } & Yes & $34(52.3)$ & $31(47.7)$ & $65(100)$ & 0.286 & \\
\hline & No & $860(45.6)$ & $1026(54.4)$ & $1886(100)$ & & \\
\hline Dyspnoea & Yes & $50(56.2)$ & $39(43.8)$ & $89(100)$ & $0.045^{\star}$ & $1.239(1.025-1.499)$ \\
\hline
\end{tabular}

${ }^{*} \mathrm{OR}$ is specified where $\mathrm{p}$ value is significant.

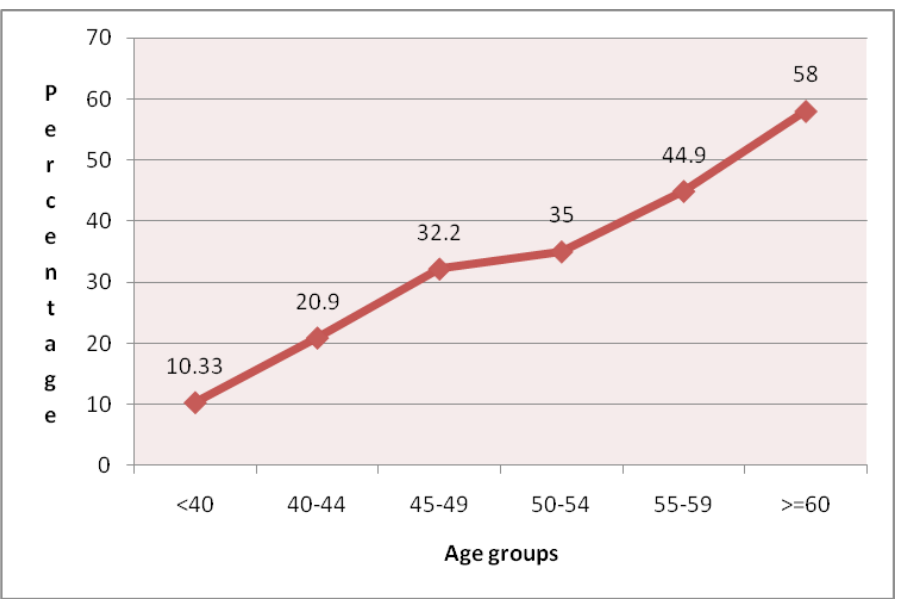

Figure 1: Percentage of diabetics in different age groups.

We did not note any difference among diabetics $(\mathrm{n}=433) \quad(\mathrm{min}=1$, $\max =57)$ and non-diabetics $(\mathrm{n}=434)(\min =1, \max =76)$ with respect to LOS in hospital $(\mathrm{p}=0.280,8.46(+8.372)$ in DM vs $(9.13(+9.979)$ in non-DM) Figure 7.

\section{Mortality in diabetics}

Two patients died while transportation through EMS, both were nondiabetics. No difference was noted in mortality among diabetics and

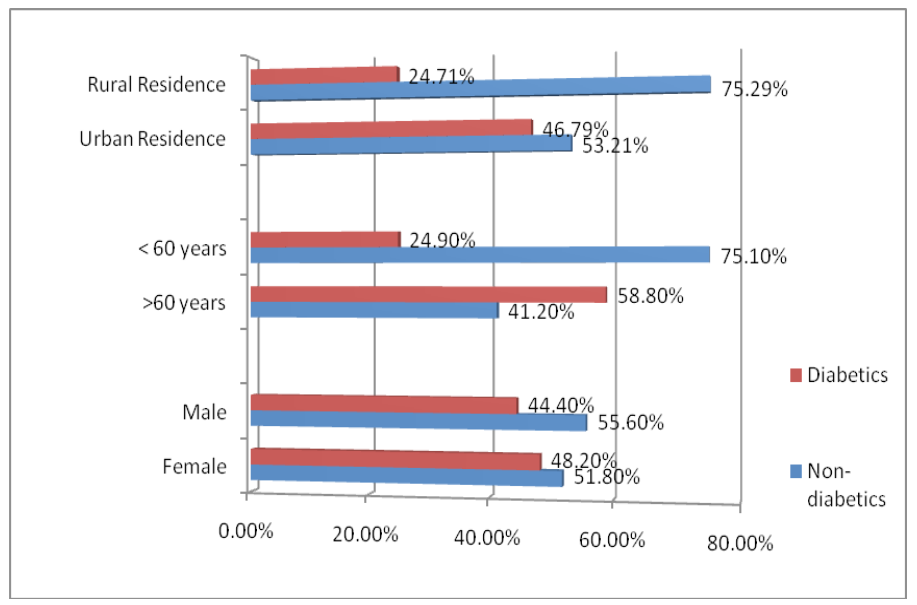

Figure 2: Age, gender and residence of Diabetics and non-diabetics.

non-diabetics (23.8\% among diabetics while $23.6 \%$ among non-diabetics, $\mathrm{p}=0.947)$. Thus, mortality did not differ among diabetics and nondiabetics $(, \mathrm{p}=0.947)$.

\section{DISCUSSION}

Many controversies are arising from literature regarding hospital stays in diabetics. The estimates in Statistical Brief based upon data from the HCUP (Healthcare cost and utilization Project) 2008, Nationwide Inpa- 


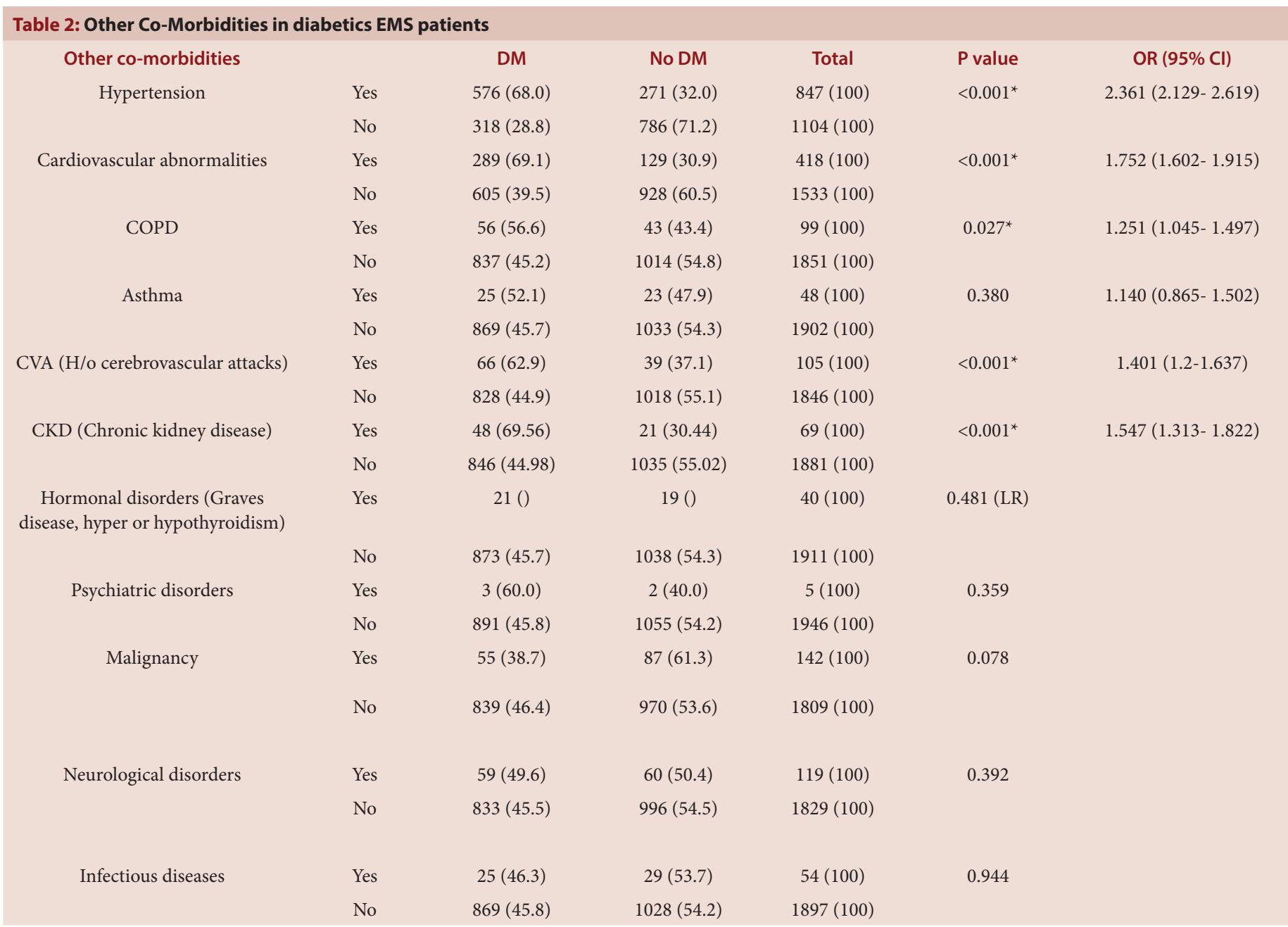

${ }^{*} \mathrm{OR}$ is specified where $\mathrm{p}$ value is significant.

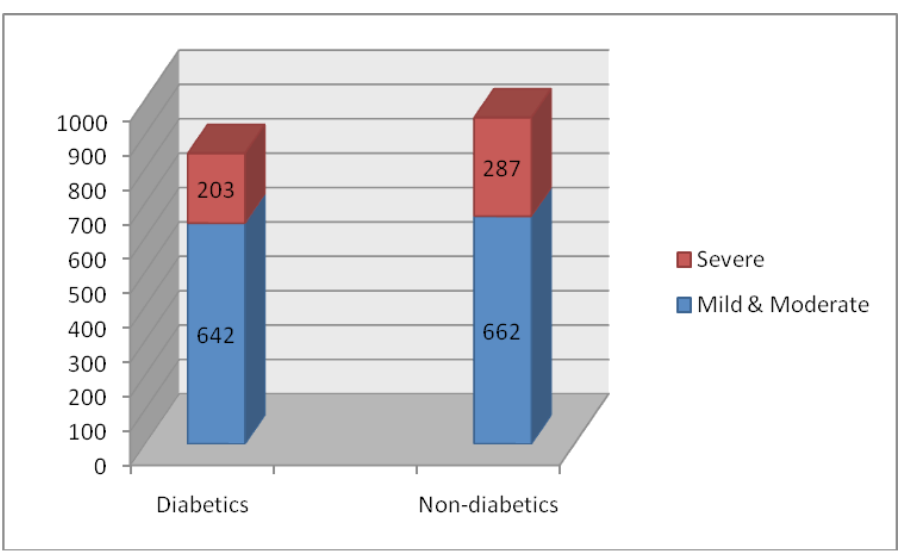

Figure 3: Severity of illness for calling EMS.

tient Sample in USA, reports that hospital stays for patients with diabetes were longer, costlier, and more likely to originate in the emergency department. ${ }^{8}$ while, there are other evidences showing lower hospital stays in diabetes units. ${ }^{16,11}$ Our study supports that diabetes is not a risk factor for ICU mortality.

Usually critically ill diabetics have one or more co-morbidities ${ }^{8}$ and their associated symptoms but they do not have an increased mortal-

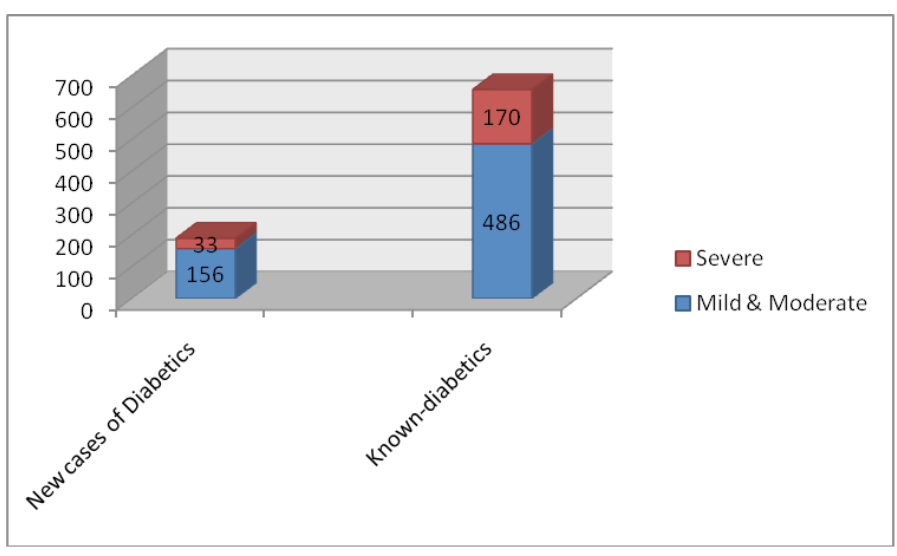

Figure 4: Severity of illness for calling EMS in new and known cases of diabetes.

ity. Instead, some studies point out that they may have decreased mortality mechanisms of which are needed to be studied further. ${ }^{11}$ But, at international level, Global Forum of Health reports, three-fold higher (18.9/1000 person years) mortality in diabetes compared to non-diabetic $(5.3 / 1000$ person-years, $\mathrm{p}=0.004){ }^{14}$

People with DM can live long and healthy lives when their diabetes is detected earlier and well managed. It can be the fruitful outcome of all 


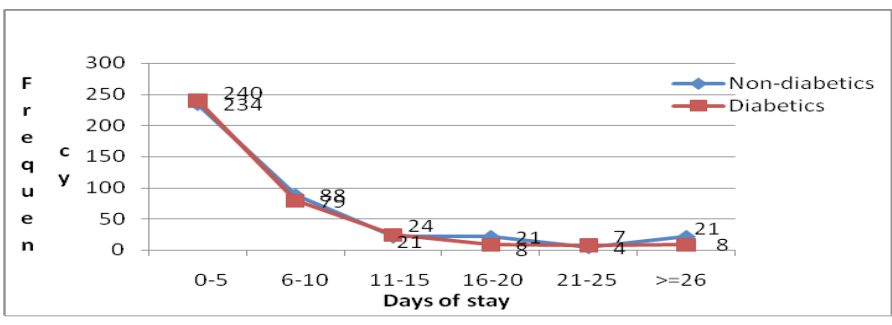

Figure 5: ICU stay for diabetics and non-diabetics.

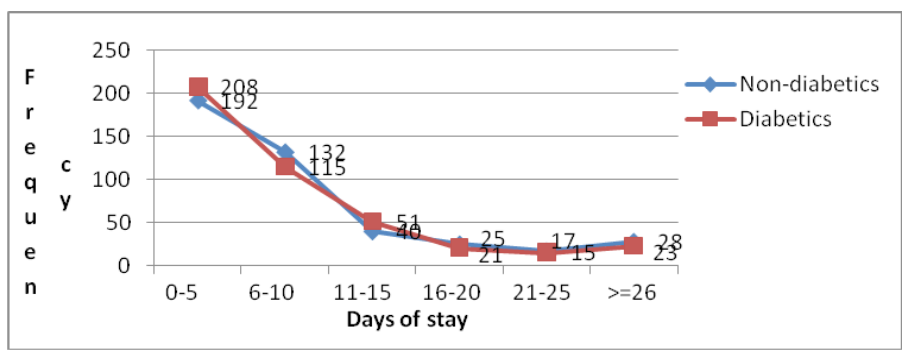

Figure 7: Total hospital stay for diabetics and non-diabetics.

awareness activities and campaigns worldwide. ${ }^{4} \mathrm{DM}$ management has undergone paradigm shift during last two decades. Increased public health education, improved insulin delivery methods, better targeting of oral hypoglycemic agents and more intensive monitoring are resulted in early metabolic control in diabetics. ${ }^{17}$ It can result in lesser severity scores among diabetics at emergency department which results in Moe favorable outcomes than expected. It also gives the reason behind controversy's in hospital stays in different studies as diabetics may have lesser control of BSL (blood sugar level), may not be diagnosed earlier and not aware of their diabetic status where DM management measures are yet under progress.

Pore sky L et al reported mean length of hospital stay for patients admitted to diabetes unit was shorter (5.8 days) than for those admitted to regular medical and surgical units (7.6 days). ${ }^{16}$ However, other studies reported that diabetes was significantly associated with a longer length of hospital stay among patients with renal abscess, by 3.38 days (95\% CI: 1.59-5.17). ${ }^{18}$

Also, EMS calls for less urgent condition among diabetics can't be ruled out. ${ }^{16}$ DM programs as advised by AHA (American Heart Association) can help to prevent emergencies and EMS calls for less urgent conditions among diabetics. They can also help to reduce cost of DM management. ${ }^{19,20}$ Implementation of such programs is the necessity in countries like India.

Although the mechanisms are not yet fully understood, now- a- days $\mathrm{DM}$ is reportedly not a risk factor for ICU mortality despite larger severity of illness at admission. ${ }^{21}$ Adaptation to hyperglycemia might be a key mechanism. It is possible that critical illness-induced oxidative stress is more harmful to non-diabetic patients than diabetics ${ }^{21,22}$ because they have not yet activated cellular adaptation mechanisms as diabetics have. Diabetics are already adapted to oxidative stress due to previous chronic exposure to hyperglycemia. We did not have the opportunity to collect data with respect to previous insulin therapy of the study subjects, but, insulin also has protective effect through anti-inflammatory properties. ${ }^{23}$ Diabetics (II) are also prone for obesity which in turn has protective effect against ICU mortality. ${ }^{24}$ Early diagnosis of diabetes, with appropriate management and lifelong follow-up, also have major impact to reduce morbidity and mortality. ${ }^{25}$

Though, the sample size is adequate which gives good precision to the estimates in this study, the only limitation of this study is that it is based

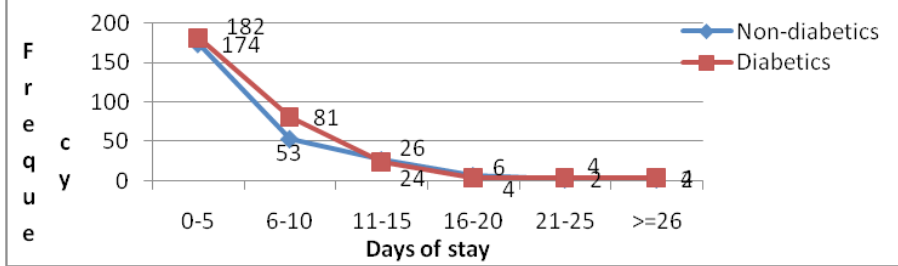

Figure 6: Ward stay for diabetics and non-diabetics.

on secondary data analysis. Emergency department (ED) utilization among diabetics is likely to be affected by several factors, including lack of primary care, duration of diabetes, presence of complications and adherence to care plans and lifestyle modifications. All these factors can also affect LOS in ICU and hospitals. Also, results of the study cannot be generalized, as it is a hospital record based study. Separate study designs are recommended to standardize results according to duration of diabetes, its management and treatment adherence that may also help to generalize the results.

\section{CONCLUSION}

The study finds no adverse impact of diabetes on outcome and hospital stays of patients attending emergency department where the study is carried out.

\section{ACKNOWLEDGEMENT}

DMH management and staff.

\section{CONFLICT OF INTEREST}

The authors are declared no conflict of interest.

\section{ABBREVIATION USED}

EMS: Emergency Medical System; p: probability value; CI: Confidence interval; OR: Odds ratio; LOS: Length of hospital Stay; DMHRC: Deenanath Mangeshkar Hospital and Research Centre; ICU: Intensive care unit; DM: Diabetes Mellitus; COPD: Chronic obstructive pulmonary disease; CKD: Chronic kidney disease; CVA: Cerebrovascular attack; GCS: Glassgow coma scale; CVS: Cardiovascular system; GIT: Gastrointenstinal system; GUT: Genito-urinary system.

\section{REFERENCES}

1. World Health Day 2016: Diabetes.WHO, India.www.searo.who.int @WHO India 2016. [Accessed on: 9/8/2016]

2. Hu FB. Globalization of Diabetes: The role of diet, lifestyle, and genes. Diabetes Care. 2011;34(6):1249-57. Published online 2011;20. doi: 10.2337/dc11-0442

3. WHO, 2016. Global report on diabetes.

4. World Health Organization. 10 facts about diabetes, 2013. Available at: http:// www.who.int/features/factfiles/diabetes/en/. [Accessed on: 9/8/2016]

5. NHP India, 2015. World Diabetes Day. www.nhp.gov.in

6. World Health Day 2016: Diabetes. WHO, India.www.searo.who.int @WHO India 2016.

7. Centers for Disease Control and Prevention. National Diabetes Fact Sheet: National Estimates and General Information on Diabetes and Pre-diabetes in the United States, 2011. Atlanta, GA: U.S. Department of Health and Human Services, Centers for Disease Control and Prevention; 2011.

8. Fraze TK, Jiang HJ, Burgess J. Hospital Stays for Patients with Diabetes, 2008. HCUP Statistical Brief \#93. August 2010. Agency for Healthcare Research and Quality, Rockville, MD. Available from: http://www.hcup-us.ahrq.gov/reports/ statbriefs/sb93.pdf. [Accessed on: 9/8/2016]

9. Brown JR, Edwards FH, O'Connor GT, Ross CS, Furnary AP. The diabetic disadvantage: historical outcomes measures in diabetic patients undergoing cardiac surgery -- the pre-intravenous insulin era. Semin Thorac Cardiovasc Surg. 2006;18(4):281-8. doi: 0.1053/j.semtcvs.2006.04.004.

10. Slynkova K, Mannino DM, Martin GS, Morehead RS, Doherty DE. The role of 
body mass index and diabetes in the development of acute organ failure and subsequent mortality in an observational cohort. Crit Care. 2006;10(5):R137. doi: $10.1186 /$ cc5051.

11. Graham BB, Keniston A, Gajic O, Alvarez CA, Medvedev S, Douglas IS. Diabetes mellitus does not adversely affect outcomes from a critical illness. Crit Care Med. 2010;38(1):16-24. doi: 10.1097/CCM.0b013e3181b9eaa5.

12. Pittet D, Thievent B, Wenzel RP, Li N, Gurman G, Suter PM. Importance of preexisting co-morbidities for prognosis of septicemia in critically ill patients. Intensive Care Med. 1993;19(5):265-72. doi: 10.1007/BF01690546.

13. Stegenga ME, Vincent JL, Vail GM, Xie J, Haney DJ, Williams MD, et al. Diabetes does not alter mortality or hemostatic and inflammatory responses in patients with severe sepsis. Crit Care Med. 2010;38(2):539-45. doi: 10.1097/ CCM.0b013e3181c02726.

14. Global Forum Health. Risk factor surveillance for non-communicable diseases (NCDs): the multi-site ICMR-WHO collaborative initiative, 2015. Available at: http://www.globalforumhealth.org/. [Accessed on: 9/8/2016]

15. Stojkovic A, Tomašević M, Krstić N, Perišić Z, Pavlović M, Šalinger-Martinović S. The effect of stress induced-hyperglycemia on hospital treatment outcome in patients with acute myocardial infarction with st segment elevation. Acta Medical Mediante. 2012;51(3).

16. Poretsky L, Koproski J, Pretto ZE. Hospital length of stay on a diabetes cluster unit. Endocr Pract. 1999;5(2):66-8.

17. Venkatesh B, Pilcher D, Prins J, Bellomo R, Morgan TJ. Incidence and outcome of adults with diabetic ketoacidosis admitted to ICUs in Australia and New Zealand. Critical Care. 2015;19(1):451.
18. Ko MC, Chiu AW, Liu CC, Liu CK, Woung LC, Yu LK, et al. Effect of diabetes on mortality and length of hospital stay in patients with renal or perinephric abscess. Clinics (Sao Paulo). 2013;68(8):1109-14. doi: 10.6061/clinics/2013(08)08.

19. Krumholz HM, Currie PM, Riegel B, Phillips CO, Peterson ED, Smith R, et al. A taxonomy for disease management: a scientific statement from the American Heart Association Disease Management Taxonomy Writing Group. Circulation. 2006;114(13):1432-45. 10.1161/CIRCULATIONAHA.106.177322.

20. Osterberg L, Blaschke T. Adherence to medication. $N$ Engl J Med. 2005;353(5):487-97. 10.1056/NEJMra050100.

21. Siegelaar SE, Devries JH, Hoekstra JB. Patients with diabetes in the intensive care unit; not served by treatment, yet protected?. Crit Care. 2010;14(2):126. doi: $10.1186 /$ cc8881

22. Motoyama T, Okamoto K, Kukita I, Hamaguchi M, Kinoshita Y, Ogawa H. Possible role of increased oxidant stress in multiple organ failure after systemic inflammatory response syndrome. Crit Care. 2003;31(4):1048-52.

23. Garg R, Chaudhuri A, Munschauer F, Dandona P. Hyperglycemia, insulin, and acute ischemic stroke: a mechanistic justification for a trial of insulin infusion therapy. Stroke. 2006;37(1):267-73. doi: 10.1161/01.STR.0000195175.29487.30.

24. Peake SL, Moran JL, Ghelani DR, Lloyd AJ, Walker MJ. The effect of obesity on 12-month survival following admission to intensive care: A prospective study. Crit Care Med. 2006;34(12):2929-39.

25. Oputa RN, Chinenye S. "Diabetes mellitus: A global epidemic with potential solutions," African Journal of Diabetes Medicine. 2012;20(2)

Cite this article : Rajhans PA, Kulkarni PY, Kelkar DS, Jog SA, Ranade G, Utpat S, Hande V. Effect of Diabetes on Severity of Illness, Length of Hospital Stay and Mortality among Patients Brought by Emergency Medical System (EMS). Int J Med Public Health. 2017;7(3):156-61. 